Article

\title{
Sorption, Solubility, Bond Strength and Hardness of Denture Soft Lining Incorporated with Silver Nanoparticles
}

\author{
Grzegorz Chladek $^{1, *}$, Jacek Kasperski ${ }^{2, \dagger}$, Izabela Barszczewska-Rybarek ${ }^{3, \dagger}$ and \\ Jarosław $\dot{Z}$ mudzki ${ }^{1, \dagger}$
}

1 Division of Materials Processing Technology, Institute of Engineering Materials and Biomaterials, Silesian University of Technology, ul. Konarskiego 18a, Gliwice 44-100, Poland; E-Mail: Jaroslaw.Zmudzki@polsl.pl

2 Department of Prosthetic Dentistry, Medical University of Silesia, pl. Akademicki 17, Bytom 41-902, Poland; E-Mail: kroczek91@interia.pl

3 Department of Physical Chemistry and Technology of Polymers, Silesian University of Technology, ul. M. Strzody 9, Gliwice 44-100, Poland; E-Mail: Izabela.Barszczewska-Rybarek@polsl.pl

$\dagger$ These authors contributed equally to this work.

* Author to whom correspondence should be addressed; E-Mail: chladek@interia.pl; Tel.: +48-32-237-29-07.

Received: 7 November 2012; in revised form: 12 December 2012 / Accepted: 17 December 2012 / Published: 27 December 2012

\begin{abstract}
The colonization of denture soft lining material by oral fungi can result in infections and stomatitis of oral tissues. In this study, $0 \mathrm{ppm}$ to $200 \mathrm{ppm}$ of silver nanoparticles was incorporated as an antimicrobial agent into composites to reduce the microbial colonization of lining materials. The effect of silver nanoparticle incorporation into a soft lining material on the sorption, solubility, hardness (on the Shore A scale) and tensile bond strength of the composites was investigated. The data were statistically analyzed using two-way ANOVA and Newman-Keuls post hoc tests or the chi-square Pearson test at the $p<0.05$ level. An increase in the nanosilver concentration resulted in a decrease in hardness, an increase in sorption and solubility, a decrease in bond strength and a change in the failure type of the samples. The best combination of bond strength, sorption, solubility and hardness with antifungal efficacy was achieved for silver nanoparticle concentrations ranging from $20 \mathrm{ppm}$ to $40 \mathrm{ppm}$. These composites did not show properties worse than those of the material without silver nanoparticles and exhibited enhanced in vitro antifungal efficiency.
\end{abstract}


Keywords: antimicrobial polymers; silver nanoparticles; soft lining; bond strength; sorption; solubility; hardness

\section{Introduction}

Permanent soft denture lining materials bonded to dentures are usually used to reduce the forces transmitted to supporting tissues. They are recommended for patients suffering from a sharp alveolar ridge or a thin atrophic mucosa, in which the mucosa shows low tolerance to the load applied by dentures and for relining in implantology [1].

One of the basic problems with using soft denture linings is the colonization of such materials by pathological microorganisms [1-3], which is fostered by the high humidity and elevated temperature found under dentures and by the material structure [4]. Fungi such as Candida albicans first adhere to a lining surface and then penetrate inside the material [1], which can lead to further infection of the oral mucosa and problems associated with stomatitis. Meanwhile, silver nanoparticles [5-7] and silver-zeolite [8] show in vitro antimicrobial effects as additives in tissue conditioners and denture base acrylic resins. Therefore, a method of incorporating silver nanoparticles into silicone soft lining materials to enhance antimicrobial efficacy was developed; the fungicidal activity of the obtained composites was confirmed in a previous study [9].

However, soft lining materials exposed to the continual influence of a humid environment can lose their soluble components [10] and absorb water [11]. The changes induced by the sorption, solubility, dehydration and oxidization of materials in a humid environment can result in the deterioration of mechanical and functional properties such as hardness and bond strength [12-14].

The purpose of this study was to evaluate the impact of silver nanoparticle incorporation into composites on the materials' sorption, solubility, hardness and tensile bond strength. The hypothesis was that, after aging in distilled water, the hardness, water sorption, solubility, and tensile bond strength of the composites depend on the concentration of silver nanoparticles.

\section{Results and Discussion}

\subsection{Results}

Introducing silver nanoparticles into Ufi Gel SC (UG) soft liner material resulted in the prolongation of the cross-linking time of the samples. The cross-linking time was observed to increase with the silver nanoparticle concentration. The cross-linking time for a composite with $40 \mathrm{ppm}$ of silver nanoparticles was approximately $15 \mathrm{~min}$ longer than that of UG, but for a material with $80 \mathrm{ppm}$ of silver nanoparticles, the cross-linking time was approximately 40 min longer. For samples featuring a silver nanoparticle concentration of $200 \mathrm{ppm}$, the cross-linking time was over $2 \mathrm{~h}$.

The nanosilver concentration had a significant influence on the mean hardness values of the composites $(p<0001)$. The hardness was observed to increase with the silver nanoparticle concentration. The aging time had no effect on hardness $(p=0.7547)$. The mean hardness values are listed in Table 1. 
Table 1. Mean hardness values in Shore A units and standard deviations.*

\begin{tabular}{cccc}
\hline Silver nanoparticle & \multicolumn{3}{c}{ Hardness, Shore A units } \\
\cline { 2 - 4 } concentration, ppm $^{n}$ & $24 \mathrm{~h}$ & 7 days & 28 days \\
\hline $\mathbf{0}$ & $31.2(0.6)^{\mathrm{A}, \mathrm{a}}$ & $31.3(0.5)^{\mathrm{A}, \mathrm{a}}$ & $31.1(0.5)^{\mathrm{A}, \mathrm{a}}$ \\
$\mathbf{1 0}$ & $28.9(0.5)^{\mathrm{B}, \mathrm{b}}$ & $28.8(0.7)^{\mathrm{B}, \mathrm{b}}$ & $28.9(0.8)^{\mathrm{B}, \mathrm{b}}$ \\
$\mathbf{2 0}$ & $28.2(0.6)^{\mathrm{C}, \mathrm{bd}}$ & $28.2(0.6)^{\mathrm{C}, \mathrm{bd}}$ & $28.1(0.7)^{\mathrm{C}, \mathrm{d}}$ \\
$\mathbf{4 0}$ & $27.5(0.7)^{\mathrm{D}, \mathrm{d}}$ & $27.5(0.7)^{\mathrm{D}, \mathrm{d}}$ & $27.6(0.7)^{\mathrm{D}, \mathrm{d}}$ \\
$\mathbf{8 0}$ & $25.9(0.4)^{\mathrm{E}, \mathrm{e}}$ & $26.3(0.5)^{\mathrm{E}, \mathrm{e}}$ & $26.2(0.8)^{\mathrm{E}, \mathrm{e}}$ \\
$\mathbf{1 2 0}$ & $22.8(0.4)^{\mathrm{F}, \mathrm{f}}$ & $22.9(0.5)^{\mathrm{F}, \mathrm{f}}$ & $22.8(0.5)^{\mathrm{F}, \mathrm{f}}$ \\
$\mathbf{2 0 0}$ & $21.4(1.0)^{\mathrm{G}, \mathrm{g}}$ & $21.3(1.1)^{\mathrm{G}, \mathrm{g}}$ & $21.3(0.8)^{\mathrm{G}, \mathrm{g}}$ \\
\hline
\end{tabular}

Notes: * Groups with the same uppercase superscript letters; (A-G) for each row and lowercase superscript letters; (a-g) for each column are not significantly different at the $p<0.05$ level.

The nanosilver concentration and aging time had a significant influence on the mean sorption values of the composites $(p<0.0001)$. The sorption increased with the aging time and the silver nanoparticle concentration, but the impact of the aging time was stronger than that of the silver nanoparticle concentration. The mean sorption values are listed in Table 2. Post hoc tests showed no statistically significant differences between the mean sorption values of UG and the nanocomposites' nanosilver concentrations from $10 \mathrm{ppm}$ to $40 \mathrm{ppm}$, regardless of the aging time used. Increasing the silver nanoparticle concentration above $80 \mathrm{ppm}$ caused an increase in sorption $(p<0.05)$. There were no significant differences $(p>0.05)$ in the sorption between 7 days and 28 days of aging up to a concentration of $40 \mathrm{ppm}$, but above $80 \mathrm{ppm}$, the sorption after 28 days was greater $(p<0.05)$ than that after 7 days.

The silver nanoparticle concentration and aging time had a significant influence on the solubility of the composites ( $p<0.0001$ and $p=0.0039$, respectively). The solubility was observed to increase with the aging time and the silver nanoparticle concentration, and the effect of the aging time was weaker than that of the silver nanoparticle concentration. The mean solubility values are listed in Table 2 . Statistically significant differences between the mean values of solubility for the samples composed of UG and composites with a silver nanoparticle concentration ranging from $10 \mathrm{ppm}$ to $120 \mathrm{ppm}$ and from $10 \mathrm{ppm}$ to $80 \mathrm{ppm}$ after 7 days and 28 days of aging, respectively, were not observed $(p>0.05)$. Only the solubility at the highest nanosilver content after 28 days was statistically greater $(p<0.05)$ than that after 7 days.

Table 2. Results of sorption and solubility investigations (mean values with standard deviations).*

\begin{tabular}{ccccc}
\hline \multirow{2}{*}{$\begin{array}{c}\text { Silver nanoparticle } \\
\text { concentration, ppm }\end{array}$} & \multicolumn{2}{c}{ Sorption, \% } & \multicolumn{2}{c}{ Solubility, \% } \\
\cline { 2 - 5 } & 7 days & 28 days & 7 days & 28 days \\
\hline $\mathbf{0}$ & $0.27(0.05)^{\mathrm{A}, \mathrm{a}}$ & $0.37(0.06)^{\mathrm{A}, \mathrm{a}}$ & $0.09(0.01)^{\mathrm{A}, \mathrm{a}}$ & $0.10(0.02)^{\mathrm{A}, \mathrm{a}}$ \\
$\mathbf{1 0}$ & $0.32(0.06)^{\mathrm{A}, \mathrm{ab}}$ & $0.41(0.06)^{\mathrm{A}, \mathrm{ab}}$ & $0.09(0.02)^{\mathrm{A}, \mathrm{a}}$ & $0.11(0.02)^{\mathrm{A}, \mathrm{a}}$ \\
$\mathbf{2 0}$ & $0.41(0.06)^{\mathrm{A}, \mathrm{ab}}$ & $0.46(0.08)^{\mathrm{A}, \mathrm{ab}}$ & $0.11(0.03)^{\mathrm{A}, \mathrm{a}}$ & $0.10(0.03)^{\mathrm{A}, \mathrm{a}}$ \\
$\mathbf{4 0}$ & $0.37(0.06)^{\mathrm{A}, \mathrm{ab}}$ & $0.51(0.09)^{\mathrm{A}, \mathrm{ab}}$ & $0.09(0.02)^{\mathrm{A}, \mathrm{a}}$ & $0.09(0.02)^{\mathrm{A}, \mathrm{a}}$ \\
$\mathbf{8 0}$ & $0.38(0.08)^{\mathrm{A}, \mathrm{ab}}$ & $0.59(0.09)^{\mathrm{B}, \mathrm{b}}$ & $0.11(0.02)^{\mathrm{A}, \mathrm{a}}$ & $0.14(0.02)^{\mathrm{A}, \mathrm{ab}}$ \\
$\mathbf{1 2 0}$ & $0.51(0.09)^{\mathrm{A}, \mathrm{b}}$ & $0.79(0.14)^{\mathrm{B}, \mathrm{c}}$ & $0.15(0.03)^{\mathrm{A}, \mathrm{a}}$ & $0.19(0.04)^{\mathrm{A}, \mathrm{b}}$ \\
$\mathbf{2 0 0}$ & $0.72(0.12)^{\mathrm{A}, \mathrm{c}}$ & $1.24(0.18)^{\mathrm{B}, \mathrm{d}}$ & $0.22(0.05)^{\mathrm{A}, \mathrm{b}}$ & $0.30(0.05)^{\mathrm{B}, \mathrm{c}}$ \\
\hline
\end{tabular}

Notes: * Groups with the same uppercase superscript letters; (A-B) for each row and lowercase superscript letters; (a-d) for each column are not significantly different at the $p<0.05$ level. 
The nanosilver concentration and aging time had a significant influence on the mean bond strength values of the composites $(p<0.0001)$, but the effect of the aging time was approximately 11 times lower than that of the nanosilver concentration. The mean bond strength values are listed in Table 3 . For individual aging times, the mean bond strength values for UG and the composites with nanosilver concentrations of 10, 20 and $40 \mathrm{ppm}$ did not differ statistically $(p>0.05)$. Above a concentration of $80 \mathrm{ppm}$, a considerable decrease in the mean bond strength values was observed. The effect of the aging time on the mean bond strength (increase of the values) was significant $(p<0.05)$ in the case of UG and the composites with nanosilver concentrations of $10 \mathrm{ppm}$ to $20 \mathrm{ppm}$, and differences were noted only between samples stored for $24 \mathrm{~h}$ and 7 days.

Table 3. Bond strength values (mean and standard deviations).*

\begin{tabular}{cccc}
\hline Silver nanoparticle & \multicolumn{3}{c}{ Bond strength, MPa } \\
\cline { 2 - 4 } concentration, ppm $^{2}$ & $24 \mathrm{~h}$ & 7 days & 28 days \\
\hline $\mathbf{0}$ & $1.18(0.17)^{\mathrm{A}, \mathrm{a}}$ & $1.53(0.17)^{\mathrm{B}, \mathrm{a}}$ & $1.48(0.29)^{\mathrm{B}, \mathrm{a}}$ \\
$\mathbf{1 0}$ & $1.29(0.24)^{\mathrm{A}, \mathrm{a}}$ & $1.62(0.23)^{\mathrm{B}, \mathrm{a}}$ & $1.51(0.31)^{\mathrm{AB}, \mathrm{a}}$ \\
$\mathbf{2 0}$ & $1.28(0.16)^{\mathrm{A}, \mathrm{a}}$ & $1.61(0.30)^{\mathrm{B}, \mathrm{a}}$ & $1.55(0.26)^{\mathrm{AB}, \mathrm{a}}$ \\
$\mathbf{4 0}$ & $1.33(0.22)^{\mathrm{A}, \mathrm{a}}$ & $1.59(0.36)^{\mathrm{A}, \mathrm{a}}$ & $1.58(0.37)^{\mathrm{A}, \mathrm{a}}$ \\
$\mathbf{8 0}$ & $0.91(0.15)^{\mathrm{A}, \mathrm{b}}$ & $0.96(0.14)^{\mathrm{A}, \mathrm{b}}$ & $0.93(0.11)^{\mathrm{A}, \mathrm{b}}$ \\
$\mathbf{1 2 0}$ & $0.51(0.06)^{\mathrm{A}, \mathrm{c}}$ & $0.54(0.02)^{\mathrm{A}, \mathrm{c}}$ & $0.52(0.02)^{\mathrm{A}, \mathrm{c}}$ \\
$\mathbf{2 0 0}$ & $0.22(0.03)^{\mathrm{A}, \mathrm{d}}$ & $0.25(0.02)^{\mathrm{A}, \mathrm{d}}$ & $0.21(0.02)^{\mathrm{A}, \mathrm{d}}$ \\
\hline
\end{tabular}

* Groups with the same uppercase superscript letters; (A-B) for each row and lowercase superscript letters; (a-d) for each column are not significantly different at the $p>0.05$ level.

The nanosilver concentration had a significant influence on the sample failure type $(p<0.0001)$ (Figure 1). For UG and composites with silver nanoparticle concentrations up to $40 \mathrm{ppm}$, adhesive failure was the dominant failure type observed, whereas at higher concentrations, the failure mechanism varied from mixed $(80 \mathrm{ppm})$ to cohesive $(200 \mathrm{ppm})$. The aging time had no effect on the failure type $(p>0.05)$.

Figure 1. Impact of the silver nanoparticle concentration on failure type after $24 \mathrm{~h}, 7$ days and 28 days of aging. A-Adhesive failure; $\mathrm{AC}-$ Mixed failure; $\mathrm{C}-$ Cohesive failure.

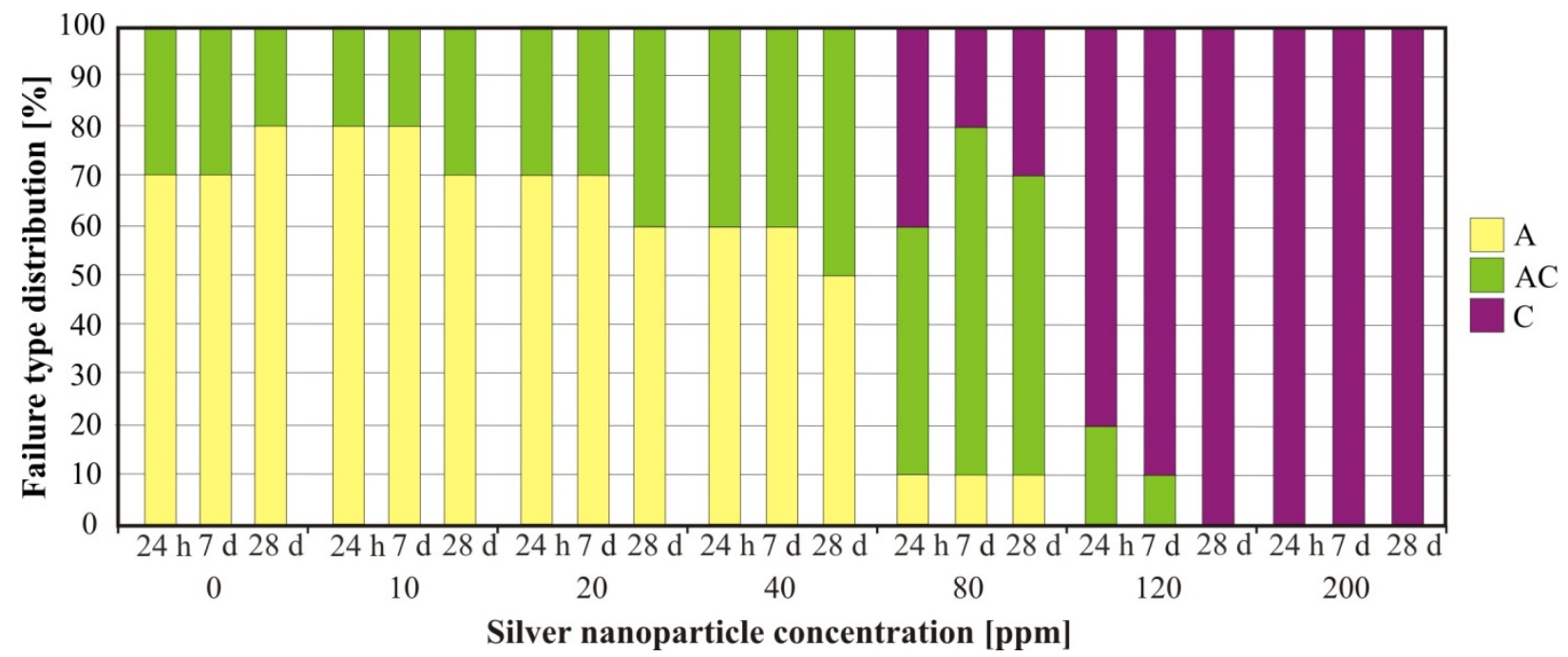




\subsection{Discussion}

The best combination of bond strength, sorption, solubility and hardness with antifungal efficacy was achieved at silver nanoparticle concentrations ranging from $20 \mathrm{ppm}$ to $40 \mathrm{ppm}$. These composites exhibited properties that were no worse than those of UG without silver nanoparticles and also demonstrated enhanced antifungal efficiency [9]. Additionally, composites with such low silver nanoparticle concentrations should not generate cytotoxicity [15], but this assumption should be confirmed in further investigations before potential clinical investigations are carried out.

All of the obtained materials were cross-linked, and the cross-linking time increased with the silver nanoparticle concentration. The prolonging of the cross-linking time was particularly noticeable starting at a silver nanoparticle concentration of $80 \mathrm{ppm}$. A decrease in the rate of polymerization and the conversion value with the silver nanoparticle concentration in the investigated polymers was also reported in [16-18]. Soriano-Corral et al. [16] reported a decrease in the rate of polymerization related to the physical interaction between the silver nanoparticles and free radicals present in the reaction medium. Fan et al. [5] assumed that the cross-linking problems associated with dental resin, which occur with increasing silver nanoparticle concentration, can be caused by the agglomeration of the silver nanoparticles. Based on previously reported SEM examinations of studied materials [9], a significant growth in the number and size of aggregates was observed starting at a silver nanoparticle concentration of $80 \mathrm{ppm}$. This implies that there is a connection between the formation of aggregates and the considerable prolonging of the cross-linking time. The nanoparticles and aggregates may physically interact with the reactive polymer groups and catalyst particles, but this assumption requires confirmation.

The mean hardness value obtained for UG is similar to that reported by Mancuso et al. [13]. For the obtained composites, the hardness decreased with the increasing concentration of silver nanoparticles. However, for concentrations from $10 \mathrm{ppm}$ to $40 \mathrm{ppm}$, the hardness values were greater than 25 Shore A; thus, these materials conform to the requirements of the ISO standard for soft lining materials [19], but composites with concentrations ranging from $80 \mathrm{ppm}$ to $200 \mathrm{ppm}$ show the hardness required for extra-soft lining materials. Changes in hardness during aging in distilled water were not observed. These results are in accordance with those of other studies that show that silicone-based materials, in contrast to acrylic-based soft linings, generally present no changes in hardness after soaking in water [20]. This can be explained by the differences in chemical composition between silicone-based and acrylic-based materials. Acrylic-based soft linings contain plasticizers that affect the initial softness of the materials [13]; thus, the loss of plasticizers causes hardening [21]. However, no plasticizer is needed to induce a softening effect in silicone-based materials because their softness is modulated by the concentration of cross-linking agent in the base rubber material [22].

Due to the problems associated with evaluating soft samples with calipers, we were forced to alter our calculations for solubility and sorption, which differed from those prescribed by ISO standards. It was noted that, during the measurements, the dimensions (particularly the diameters) of the samples were unintentionally deformed; thus, it was concluded that the results would not be accurate. Such problems do not occur when measuring sample mass; therefore, the percentage changes in mass were determined. This method of calculating the sorption and solubility has been reported in the literature [13] but does not allow for a comparison of the results with those of a standard. The mean 
sorption and solubility values obtained for UG and composites with silver concentrations of up to 200 ppm were smaller than those reported by Mancuso et al. [13]; however, their experiments were not performed after soaking in distilled water but after 2000 thermal cycles. Nevertheless, the sorption and solubility of the composites were comparable to those reported for other silicone-based materials, including the similar Ufi Gel P, after 1 week and 4 weeks of aging in distilled water [23]. Moreover, the mean sorption and solubility values of composites containing a wide range of silver nanoparticle concentrations (up to $120 \mathrm{ppm}$ ) were comparable to those obtained for UG. It should be emphasized that silicone-based materials generally exhibit much lower sorption and solubility than acrylic-based lining materials because they do not contain components such as plasticizers that are rinsed out by water and consequently allow water absorption [16-18,20,21,24-26].

The bond quality of lining materials with denture base materials is usually determined by three commonly accepted methods: peel, shear and tensile tests $[25,26]$. However, these laboratory tests do not fully reflect the clinical bond strength of soft lining materials because they only allow for the analysis of one type of material load, whereas materials in the oral cavity are exposed to various loads due to forces that act over long periods [24]. Still, these methods are especially useful for comparing the bond strength and failure type of certain lining materials. The tensile test is preferred when examining strength [26] and is standardized by the ISO [19]. Nevertheless, there may be some difficulties in interpretation, mainly due to the failure type of a given set of samples. Lining materials exhibit a relatively low tensile strength that is quite frequently lower than the bond strength. This results in cohesive or adhesive-cohesive failure in samples. In fact, the strength of a lining material or the combination of a material's strength and bond strength is often measured instead of the bond strength alone. In such cases, the bond strength is noted to be higher than the tensile strength of the material tested.

The mean bond strength obtained for UG is similar to the values reported by Mutluay et al. [26] and Lassila et al. [27]. A significant deterioration in the mean bond strength and changes in the failure type from adhesive to mixed to cohesive were observed starting at silver nanoparticle concentrations of $80 \mathrm{ppm}$. This indicates that the tensile strength of those materials was greatly reduced. Composites containing silver nanoparticle concentrations of up to $40 \mathrm{ppm}$ conform to the ISO standard requirements for soft lining materials (the bond strength after $24 \mathrm{~h}$ of soaking in distilled water was higher than $1 \mathrm{MPa}$ in at least 8 out of each 10 samples). Materials with a silver nanoparticle concentration of $80 \mathrm{ppm}$ were classified as extra soft, but materials with higher silver nanoparticle concentrations did not fulfill the ISO standard requirements.

The mean bond strength of UG and composites with silver nanoparticle concentrations of up to $40 \mathrm{ppm}$ did not differ statistically. For those materials, an increase in the mean bond strength was observed after seven days of aging. Yanikogtlu et al. [28] also noted that, after the first seven days of aging in distilled water, artificial saliva, coffee and tea, the bond strength of Ufi Gel P material increased. Mutluay et al. [26] reported that silicone materials bonded with an acrylic base material previously stored in distilled water exhibited a higher bond strength than that of a dry acrylic substrate. They concluded that this phenomenon could be caused by the interfacial reactions that take place when wet denture base resin samples were used. These reactions can lead to interpenetration and cross-linking, which result in the formation of a more organized structure [27]. This may explain not only the higher bond strength obtained due to the application of wet denture base materials but also the increase in 
bond strength observed after seven days of aging in distilled water. The decrease in the mean bond strength values noted after 28 days was not statistically significant. The bond strength of the similar Ufi Gel P soft liner reported by Aydin et al. [14] and Yanikoglu et al. [28] after 30 days of aging in water decreased; however, Yanikoglu et al. [28] reported a much greater decrease in bond strength than Aydin et al. [14]. These differences may be due to material type, the methods of sample preparation or test parameters such as the cross-head speed of the testing machine used throughout the course of examinations.

The negative consequences of introducing nanoparticles into the composites considered in this study on the hardness, sorption, solubility and bond strength of the materials were associated with the observed prolonging of the cross-linking time. If composites with silver nanoparticle concentrations of up to $40 \mathrm{ppm}$ presented properties similar to those of UG, the composites with higher concentrations of nanoparticles were even more weakly cross-linked, which adversely affected the other properties investigated. Additionally, a prolonged cross-linking time may create difficulties during a direct relining in the mouth. In any event, the results obtained in this study should be considered together with those previously reported on antifungal activity [9]. In an environment containing UG specimens, an increase of $23.4 \%$ in the CFU/mL value of Candida albicans was observed (in comparison to a positive control). This result indicates that soft liners can support fungal growth and corresponds well with the results reported by Pavan et al. [2]. The antifungal efficiencies (AFEs) of composites (relative to a positive control) ranged from $16.3 \%$ for a composite with $10 \mathrm{ppm}$ of nanosilver to $52.2 \%$ obtained for a composite with $200 \mathrm{ppm}$ of nanosilver (thus, the reduction in the presence of fungi related to UG ranged from $39.7 \%$ to $75.6 \%$ ). The most effective treatment was an increase in the silver nanoparticle concentration to $40 \mathrm{ppm}$, for which the AFE value was $31.5 \%$. Further increasing the nanosilver concentration from $40 \mathrm{ppm}$ to $200 \mathrm{ppm}$ was less effective: a quintuple increase in concentration increased the antifungal efficacy by only an additional $28 \%$. The reduced effectiveness of increasing doses of silver introduced into the composites is related to the previously reported increase in the number and size of aggregates: scanning electron microscopy measurements indicated the presence of individual particles and nanoparticle aggregates in all composites; however, above a concentration of $80 \mathrm{ppm}$, the size of the aggregates that formed mostly ranged between $100 \mathrm{~nm}$ and $300 \mathrm{~nm}$, with the size some large aggregates exceeding $1 \mu \mathrm{m}$ [9]. The aggregation of nanosilver reduces the effective surface area of the nanoparticles and silver ion emission, which reduces the particles' antimicrobial effect [15]. Additionally, it should be taken into account that the results of antifungal in vitro tests are not confirmation of clinical relevance but, together with hardness, sorption, solubility and bond strength tests, may be a good starting point for cytotoxicity and in vivo investigations.

\section{Experimental Section}

The composites were prepared by the previously described method [9]. The silicone soft liner UG (VOCO: Cuxhaven, Germany) and a $30 \mathrm{ppm}(\mathrm{w} / \mathrm{w})$ silver nanoparticle colloid in n-hexane (Amepox Ltd.: Łódź, Poland) were used to prepare the composites. The average nanoparticle size of the colloid, as confirmed by dynamic light scattering (DLS), was $22.8 \mathrm{~nm}$ [9].

Silver nanoparticles were introduced separately into both components of the UG material: the UG base (mixture of polyalkylsiloxanes, fumed silica and pigments) and UG catalyst (mixture of 
polyalkylsiloxanes and catalyst). The UG components were dissolved in hexane by stirring with a magnetic stirrer at room temperature for $2 \mathrm{~h}$, achieving a concentration of $7 \%(\mathrm{w} / \mathrm{w})$. The silver nanoparticle colloid mass required to produce a component with a particular concentration was calculated according to the following equation:

$$
m_{A g H}=\frac{c_{A g m} \times m_{m} \times 10^{6}}{c_{A g H} \times\left(10^{6}-c_{A g m}\right)}
$$

where $m_{\mathrm{AgH}}$ is the silver nanoparticle colloid mass $(\mathrm{g}), c_{\mathrm{Agm}}$ is the silver nanoparticle concentration in a given composite component $(\mathrm{ppm}), m_{\mathrm{m}}$ is the $\mathrm{UG}$ component mass $(\mathrm{g})$ and $c_{\mathrm{AgH}}$ is the silver nanoparticle concentration in the hexane colloid.

The colloid mass calculated according to Equation 1 was added to the solution of a modified component, and the mixture was stirred with a magnetic stirrer for $15 \mathrm{~min}$.

Next, the hexane was evaporated from the mixtures using a two-step procedure. First, it was preliminarily evaporated under a reduced pressure of $100 \mathrm{mbar}$ in a rotary evaporator (IKA RV-10 rotary evaporator equipped with Vacuubrand DVR 2 vacuum meter); then, the condensed composition was poured into a Petri dish and warmed in a dryer at $50{ }^{\circ} \mathrm{C}$ for $24 \mathrm{~h}$.

According to this procedure, both the UG base and the UG catalyst were modified to obtain the following silver nanoparticle concentrations: 10, 20, 40, 80, 120 and $200 \mathrm{ppm}$. During the cross-linking of the samples, components with the same silver nanoparticle concentration were mixed together in a mass ratio of $1: 1$; thus, six different composites were fabricated and examined. Before testing the samples for hardness, sorption, solubility and bond strength, a simple test was carried out to define the changes in the cross-linking time of the composites. Five samples of each material $(40 \mathrm{~mm}$ in diameter and $6 \mathrm{~mm}$ in thickness) were tested. Cross-linking was carried out at $45{ }^{\circ} \mathrm{C}$, the temperature recommended by the manufacturer. During the test, measurements of sample hardness on the Shore A scale were repeated in 5 min intervals until the same value was registered four times in a row (no registered increase in hardness for $20 \mathrm{~min}$ ). The period spanning from the start of the experiment to the final hardness measurements was accepted as the cross-linking time.

The hardness after $5 \mathrm{~s}$ of loading was measured using a method presented in the ISO standard [19], but in this study, measurements were taken after three storage times. An HDA 100-1 Shore A Digital Durometer (Zwick GmbH \& Com: Ulm, Germany) was used to measure the hardness. Material components were mixed manually, and samples measuring $40 \mathrm{~mm}$ in diameter and $6 \mathrm{~mm}$ in thickness were created in a steel mold. Three samples were created for every material $(n=21)$. The hardness was measured after $24 \mathrm{~h}, 7$ days and 28 days of aging in distilled water at $37 \pm 1{ }^{\circ} \mathrm{C}$. The hardness of every sample after each aging time was measured at five measurement points, which were at least $5 \mathrm{~mm}$ from the edge of each sample and spaced at least $2 \mathrm{~mm}$ away from each other. When the measurement was completed, the sample was immediately reimmersed in water.

The sorption and solubility of the obtained composites were determined using a method based on the ISO standard [19], with some modifications made with respect to the aging time and the method of calculation. Material components were mixed manually, and test samples measuring $50 \mathrm{~mm}$ in diameter and $0.5 \mathrm{~mm}$ in thickness were created in stainless steel molds. Cross-linked samples were removed from the mold using tweezers, and their quality was examined to determine whether the 
surfaces were flat or contained any bubbles. Ten samples of each material were created $(n=70)$. The samples were weighed on an AS 110/C/2 analytic scale (Radwag: Radom, Poland) with a measurement accuracy of $0.1 \mathrm{mg}$ and were placed inside desiccators containing freshly dried silica gel. The desiccators were placed in a dryer at $37 \pm 1{ }^{\circ} \mathrm{C}$, and the samples were weighed every $24 \mathrm{~h}$. These measurement cycles were repeated until the daily changes in mass were no higher than $0.2 \mathrm{mg}$. Stable values were registered as $\mathrm{m}_{1}$ "conditioned mass", and the samples were placed in a chamber filled with distilled water (POCH: Gliwice, Poland) at $37 \pm 1{ }^{\circ} \mathrm{C}$. Two aging times were used: 7 days and 28 days. After aging, the samples were removed from water, and all visible moisture was removed using filter paper; the samples were air-dried for approximately $15 \mathrm{~s}$ and then weighed. The registered mass was denoted $\mathrm{m}_{2}$. The samples were placed in desiccators with freshly dried silica gel and dried until they reached a stable mass, denoted as $m_{3}$. The sorption and solubility of each sample were calculated using the following equations [13]:

$$
\begin{aligned}
& w_{\mathrm{gp}}=\frac{m m_{2}-m_{3}}{m m_{1}} \times 100 \% \\
& w_{\mathrm{gl}}=\frac{m m_{1}-m m_{3}}{m m_{1}} \times 100 \%
\end{aligned}
$$

where $w_{\mathrm{sp}}$ is sorption, $w_{\mathrm{sl}}$ is solubility, $m_{1}$ is the initial mass of dried samples, $m_{2}$ is the mass after aging, and $m_{3}$ is the mass after the second drying step.

The tensile bond strength between the UG liner or composites and the denture base resin was measured by a slightly modified version of the method presented in the ISO standard [19]. Heat-cured PMMA resin Vertex Rapid Simplified (Vertex-Dental B.V.: Zeist, The Netherlands) plates $(100 \mathrm{~mm} \times 100 \mathrm{~mm})$ were prepared. The plates were preliminarily ground on abrasive papers (Struers A/S: Copenhagen, Denmark) in the grit size sequence 120, 220 and 320 to eliminate any possible unevenness and to standardize the plates' thickness. Following this grinding process, the thickness of the plates was $3.1 \pm 0.2 \mathrm{~mm}$. The plates were cut into square pieces measuring $25 \mathrm{~mm}$ on a side. The obtained PMMA samples were thoroughly rinsed, and their working surfaces were wet-ground by 500-grit abrasive paper to remove the scratches made by the previous grinding procedure. The prepared samples were placed in distilled water and stored at $37 \pm 1^{\circ} \mathrm{C}$ for 28 days $\pm 5 \mathrm{~h}$. After aging, they were taken out in pairs from the bath; the surface of the samples was dried with filter paper, and the bonding agent Ufi Gel SC Adhesive (VOCO: Cuxhaven, Germany) was applied with a brush. The first plate was placed on the compression table mounted to the testing machine. Next, a polyethylene ring with an internal diameter of $11 \mathrm{~mm}$ and a thickness of $3 \mathrm{~mm}$ was placed in the middle of the plate. The test material was manually mixed and injected into the ring; then, a second acrylic plate was placed over the material, and the material was compressed with a force of $30 \mathrm{~N}$. When the tested material was cross-linked, a handle was fixed by an auto-polymer to the sample. Thirty samples were made from each material $(n=210)$. The samples were aged in distilled water at $37 \pm 1{ }^{\circ} \mathrm{C}$ for $24 \pm 1 \mathrm{~h}, 7$ days $\pm 1 \mathrm{~h}$ and 28 days $\pm 2 \mathrm{~h}$. As soon as the samples were taken out of the bath, they were immediately mounted in the jaws of the testing machine (Zwick GmbH \& Com: Ulm, Germany), which was equipped with prepared handles, and tensile testing was performed at a cross-head speed of $10 \mathrm{~mm} / \mathrm{min}$. The bond strength $\sigma_{B}(\mathrm{MPa})$ was calculated according to the following equation: 


$$
\sigma_{\mathrm{E}}=\frac{F_{\max }}{A}
$$

where $F_{\max }$ is the maximum force $(\mathrm{N})$ and $A$ is the initial surface area of the bond between the silicone and resin $\left(\mathrm{mm}^{2}\right)$.

Additionally, the failure type was defined visually for each sample [26] as being adhesive (interfacial), cohesive (complete bulk) or mixed adhesive and cohesive (Figure 2).

Figure 2. Diagrammatic presentation of the test procedure for determination of tensile bond strength and failure type.

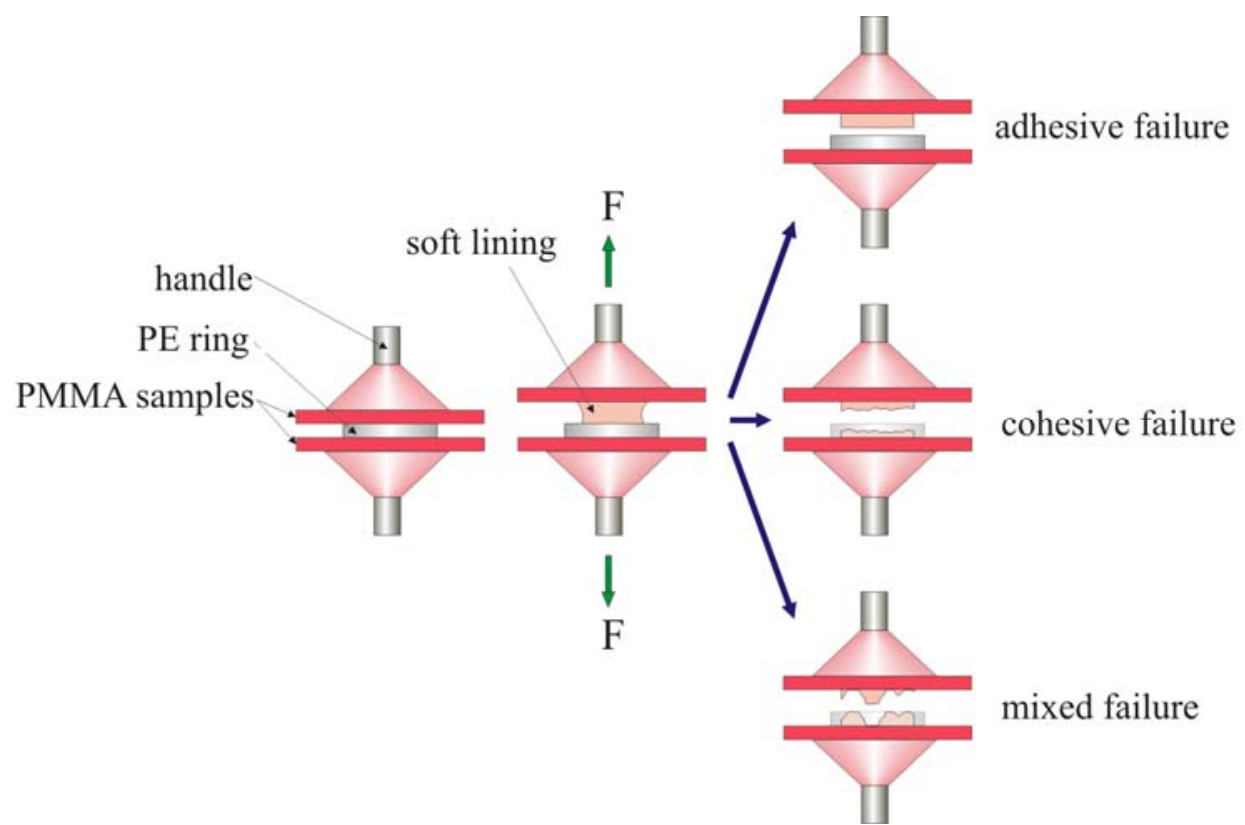

The results of the sorption, solubility, tensile bond strength and hardness tests were statistically evaluated using the two-way analysis of variance (ANOVA) (silver nanoparticle concentration and storage time). The Newman-Keuls significant difference post hoc test was used to determine the differences between mean values. Statistical significance was defined at $p<0.05$. The impact of the silver nanoparticle concentration and the sample aging time in distilled water on the type of failure observed was defined by the chi-square $\left(\chi^{2}\right)$ Pearson test. Statistical significance was defined at $p<0.05$.

\section{Conclusions}

The hypothesis that the hardness, absorption, solubility and tensile bond strength of composites after artificial aging are dependent on silver nanoparticle concentration was confirmed. Composites with silver nanoparticle concentrations of up to $40 \mathrm{ppm}$ presented properties that were no worse than those of the UG liner material. Starting at a concentration of $80 \mathrm{ppm}$, the hardness and tensile bond strength of the composites were greatly reduced, while the absorption and solubility increased due to problems associated with the cross-linking of the composites. 


\section{Acknowledgements}

This study was funded by the Ministry of Science and Higher Education by research project N N518 425836.

\section{Conflict of Interest}

The authors declare no conflict of interest.

\section{References}

1. Bulad, K.; Taylor, R.L.; Verran, J.; McCord, J.F. Colonization and penetration of denture soft lining materials by Candida albicans. Dent. Mater. 2004, 20, 167-175.

2. Pavan, S.; dos Santos, P.H.; Filho, J.N.; Spolidorio, D.M. Colonisation of soft lining materials by micro-organisms. Gerodontology 2010, 27, 211-216.

3. Taylor, R.L.; Bulad, K.; Verran, J.; McCord, J.F. Colonization and deterioration of soft denture lining materials in vivo. Eur. J. Prosthodont. Restor. Dent. 2008, 16, 50-55.

4. Nikawa, H.; Hamada, T.; Yamamoto, T.; Kumagai, H. Effects of salivary or serum pellicles on the Candida albicans growth and biofilm formation on soft lining materials in vitro. J. Oral. Rehabil. 1997, 24, 594-604.

5. Fan, C.; Chu, L.; Rawls, H.R.; Norling, B.K.; Cardenas, H.L.; Whang, K. Development of an antimicrobial resin-A pilot study. Dent. Mater. 2011, 27, 322-328.

6. Nam, K.Y.; Lee, C.H.; Lee, C.J. Antifungal and physical characteristics of modified denture base acrylic incorporated with silver nanoparticles. Gerodontology 2012, 29, 413-419.

7. Nam, K.Y. In vitro antimicrobial effect of the tissue conditioner containing silver nanoparticles. J. Adv. Prosthodont. 2011, 3, 20-24.

8. Abe, Y.; Ishii, M.; Takeuchi, M.; Ueshige, M.; Tanaka, S.; Akagawa, Y. Effect of saliva on an antimicrobial tissue conditioner containing silver-zeolite. J. Oral. Rehabil. 2004, 31, 568-573.

9. Chladek, G.; Mertas, A.; Barszczewska-Rybarek, I.; Nalewajek, T.; Zmudzki, J.; Król, W.; Lukaszczyk, J. Antifungal activity of denture soft lining material modified by silver nanoparticles-A pilot study. Int. J. Mol. Sci. 2011, 12, 4735-4744.

10. Jones, D.W.; Sutow, E.J.; Hall, G.C.; Tobin, W.M.; Graham, B.S. Dental soft polymers, plasticizer composition and leachability. Dent. Mater. 1988, 4, 1-7.

11. Braden, M.; Wright, P.S. Water absorption and water solubility of soft lining materials for acrylic dentures. J. Dent. Res. 1983, 62, 764-768.

12. Kawano, F.; Dootz, E.R.; Koran, A., 3rd; Craig, R.G. Sorption and solubility of 12 soft denture liners. J. Prosthet. Dent. 1994, 72, 393-398.

13. Mancuso, D.N.; Goiato, M.C.; Zuccolotti, B.C.; Moreno, A.; dos Santos, D.M.; Pesqueira, A.A. Effect of thermocycling on hardness, absorption, solubility and colour change of soft liners. Gerodontology 2012, 29, 215-219.

14. Aydin, A.K.; Terzioğlu, H.; Akinay, A.E.; Ulubayram, K.; Hasirci, N. Bond strength and failure analysis of lining materials to denture resin. Dent. Mater. 1999, 15, 211-218. 
15. Kvitek, L.; Panacek, A.; Prucek, R.; Soukupova, J.; Vanickova, M.; Kolar, M.; Zboril, R. Antibacterial activity and toxicity of silver-Nanosilver versus ionic silver. J. Phys. Conf. Ser. 2011, 304, 012029:1-012029:8, doi:10.1088/1742-6596/304/1/012029.

16. Soriano-Corral, F.; Morales, G. Nanocomposites based on high impact polystyrene/silver nanoparticles: Effect of silver nanoparticles concentration on the reaction evolution, morphology, and impact strength. Polym. Eng. Sci. 2011, 51, 1866-1874.

17. Yeum, J.H.; Sun, Q.; Deng, Y. Poly(vinyl acetate)/silver nanocomposite microspheres prepared by suspension polymerization at low temperature. Macromol. Mater. Eng. 2005, 290, 78-84.

18. Yeum, J.H.; Ghim, H.D.; Deng, Y. Low temperature suspension polymerization of methyl methacrylate for the preparation of high molecular weight poly(methyl methacrylate)/silver nanocomposite microspheres. Fiber. Polym. 2005, 6, 277-283.

19. ISO International Organization for Standardization. EN ISO 10139-2:2009 Dentistry-Soft Lining Materials for Removable Dentures - Part 2: Materials for Long-Term Use, 2009.

20. Yoeli, Z.; Miller, V.; Zeltser, C. Consistency and softness of soft liners. J. Prosthet. Dent. 1996, 75, 412-418.

21. Mese, A.; Guzel, K.G. Effect of storage duration on the hardness and tensile bond strength of silicone and acrylic resin-based resilient denture liners to a processed denture base acrylic resin.

J. Prosthet. Dent. 2008, 99, 153-159.

22. Polyzois, G.L.; Frangou, M.J. Influence of curing method, sealer, and water storage on the hardness of a soft lining material over time. J. Prosthodont. 2001, 10, 42-45.

23. Dinçkal Yanikoglu, N.; Yeşil Duymuş, Z. Comparative study of water sorption and solubility of soft lining materials in the different solutions. Dent. Mater. J. 2004, 23, 233-239.

24. Al-Athel, M.S.; Jagger, R.G. Effect of test method on the bond strength of a silicone resilient denture lining material. J. Prosthet. Dent. 1996, 76, 535-540.

25. Elias, C.N.; Henriques, F.Q. Effect of thermocycling on the tensile and shear bond strengths of three soft liners to a denture base resin. J. Appl. Oral. Sci. 2007, 15, 18-23.

26. Mutluay, M.M.; Ruyter, I.E. Evaluation of bond strength of soft relining materials to denture base polymers. Dent. Mater. 2007, 23, 1373-1381.

27. Lassila, L.V.; Mutluay, M.M.; Tezvergil-Mutluay, A.; Vallittu, P.K. Bond strength of soft liners to fiber reinforced denture base resin. J. Prosthodont. 2010, 19, 620-624.

28. Yanikoglu, N.; Denizoglu, S. The effect of different solutions on the bond strength of soft lining materials to acrylic resin. Dent. Mater. J. 2006, 2, 39-44.

(C) 2013 by the authors; licensee MDPI, Basel, Switzerland. This article is an open access article distributed under the terms and conditions of the Creative Commons Attribution license (http://creativecommons.org/licenses/by/3.0/). 